\title{
SOME POSSIBLE INTERACTIONS BETWEEN GLICLAZIDE AND NEBIVOLOL IN EXPERIMENTALLY INDUCED DIABETIC HYPERTENSIVE ALBINO RATS
}

\author{
Nabila H.F. El-Baroudy, Fawkia A. Fayed, Ameen M.M.Sekinah, Amal E. Salim \\ Clinical Pharmacology Department, Faculty of Medicine ,Zagzig University
}

\begin{abstract}
Background: Diabetes mellitus is common in patients with hypertension ,also, hypertension is more frequent in the diabetics than in the non-diabetic individuals. Genetics, environment, hormones, and other pathophysiologic factors contribute to this relationship. Drug therapy of hypertension with diabetes has been surrounded by a controversy because concurrent administration of antihypertensive and anti-diabetic agents is a common trend.

Objectives: This work was designed to study some interactions between gliclazide(anti-diabetic) and nebivolol (antihypertensive) in experimentally induced diabetic hypertensive albino rats

Methods: 50 adult male albino rats were used. They were divided into the following groups: G1: Non diabetic normotensive control $(\mathrm{CN})$, Other 40 rats were subjected to induction of type $2 \mathrm{DM}$ and hypertension by streptozotocin (STZ), the diabetic -hypertensive rats were selected and divided into 4 groups: G2: diabetic-hypertensive (DH) control ,G3: DH gliclazide treated (5mg/kg/day) ,G4: nebivolol treated (10 mg/kg/day), G 5: DH gliclazide \& nebivolol treated . After 8 weeks treatment, the following parameters were estimated: fasting blood glucose (FBG), mean arterial blood pressure (MABP), Serum insulin, nitric oxide (NO), superoxide dismutase (SOD), malondialdehyde (MDA), lipid profile in addition to the response of isolated aortic strips to noradrenaline before and after acetylcholine

Results: Nebivolol, significantly $(\mathrm{p}<0.05)$ decreased the elevated FBG,MABP,MDA and increased serum NO and SOD activity and improved NO dependent vasorelaxation response of aorta when compared with G2 group. Also, it significantly decreased LDL, TC. Furthermore nebivolol improved these parameters when administrated with gliclazide more than nebivolol alone.

Conclusion: concurrent administration of nebivolol and gliclazide, improved many metabolic parameters, oxidative stress and vascular reactivity more than when each drug was administrated alone in experimentally induced diabetic hypertensive rats.
\end{abstract}

Key words: Gliclazide, nebivolol, interaction, diabetic-hypertensive, rates.

\section{INTRODUCTION}

D iabetes mellitus (DM), is the most common cause of morbidity and mortality in modern civilization. It is a pervasive and multifactorial metabolic syndrome which characterized by imperfection in insulin secretion and insulin receptor or post-receptor events with derangement in carbohydrate, protein, and lipid metabolism ${ }^{(1)}$. DM is of two types IDDM (insulin dependent diabetes mellitus or type1diabetes) and NIDDM (non-insulin dependent diabetes mellitus or type2 diabetes). IDDM is associated with sever impairment in the secretion of insulin from the $\beta$ cells of pancreas while NIDDM is the consequence of decrease in the insulin secretion and insulin resistance $^{(2)}$.

The major disorders of diabetes includes hyperglycemia, hyperlipidemia, cardiovascular diseases, nephropathy and retinal damage ${ }^{(3)}$.

In diabetes, oxidative stress plays an important role due to increase production of reactive oxygen species (ROS) which leads to tissue damage and diabetic complications ${ }^{(\mathbf{4})}$. This enhances oxidative stress results in detrimental cellular and extracellular matrix (ECM) remodeling in end organs, (including the endocrine pancreas). It, also, leads to increase in vascular ROS which reduces nitric oxide synthase (NOS) expression and activity and/or NO availability ${ }^{(5)}$.

Hypertension and type 2 diabetes mellitus associated with substantially increase cardiovascular diseases morbidity, mortality, and chronic kidney diseases. Patients with newly diagnosed T2DM, more than half of them have coexisting hypertension, and approximately 50\%, patients with hypertension develop T2DM over a 10- to 15-years period, environment, hormones, and other pathophysiologic factors contribute to this relationship ${ }^{(6)}$.

In diabetic patients, there are many risk factors which may contribute to the pathogenesis of hypertension by promoting kidney diseases and vascular stiffness ${ }^{(7)}$. Hyperinsulinemia, in DM, stimulates the sympathetic nervous system and the renin-angiotensin-aldosterone system (RAAS), which can cause kidney and vascular damage through both hemodynamic and non-hemodynamic pathways ${ }^{(6)}$.

Gliclazide, a second-generation sulphonylurea, is widely used in the treatment of type 2 diabetes and characterized by high affinity and strong selectivity to pancreatic sulphonylurea reseptores $^{(8)}$. Gliclazide also has antioxidant properties that are independent of its effects on glucose, which might explain the beneficial effects of the drug beyond its anti-hyperglycaemic activity so,it may protect pancreatic beta-cells from the deleterious effects of reactive oxygen species through its antioxidant effect ${ }^{(9)}$. Also, gliclazide can improve endothelial dysfunction and this effect is likely related ,also, to its antioxidant effect ${ }^{(\mathbf{1 0})}$. 
Nebivolol is a third generation $\beta$ adrenergic receptor-blocking drug. It is a racemic mixture of $\mathrm{D}$ - and L-enantiomers, of which $\mathrm{D}$ nebivolol is considered to be a highly selective $\beta$ adrenergic receptor antagonist and the L-isomer determines the stimulation of eNOS and subsequent endothelium-dependent vasodilation (11).

The pharmacological treatment of patients with hypertension and DM has been surrounded by controversy, because the concurrent administration of antihypertensive and antidiabetic agents is mandatory ${ }^{(\mathbf{1 2})}$.

In this study, we investigated some possible pharmacodynamic interactions between nebivolol and gliclazide in experimentally induced diabetic hypertensive rats, to see whether it improves or worsens the measured parameters.

\section{Drugs and Chemicals \\ MATEREALS AND METHODS}

-Nebivolol:5mg tablets, Marcyrl-pharmaceutical industries-Elobour City-Egypt. • Gliclazide tablets: SIGMA- pharmaceutical industries. Egypt. S.A.E, (These two drugs were freshly prepared in distilled water before administration through gavage tube) -Ethyl Carbamate (Urethane) crystals; Prolabo, Paris, -Nicotinamide powder: E.I.P.I.Co. A.R.E., -Streptozotocin powder: Sigma-Aldrich (St. Louis, MO, USA), -Noradrenaline bitartarate powder: (sigma company England), •Acetylcholine powder: (Fluka Chemika), $\cdot$ Normal saline solution $(\mathrm{NaCl}$ 0.9\%); Nile Co., Egypt. kits for estimation of Serum insulin, nitric oxide(NO), superoxide dismutase (SOD), malondialdehyde (MDA) and lipid profile(cholesterol, triglyceride LDL and HDL)

\section{Experimental animals:}

The study was started on 50 adult male albino rats weighting 180-200 gm/rat, purchased from the Faculty of Veterinary Medicine, Zagazig University, Egypt. The rats were fed on standard diet, with free access to tap water, housed in metal cages, each cage about $60 \times 80 \times 30 \mathrm{~cm}$ containing 10 rats.

\section{Experimental protocol:}

The animals were divided into the following groups:

G1: Non diabetic normotensive control group (10 rats) were subjected to single intra-peritoneal (I.P.) injection of saline solution. After one month, the animals received distilled water by using gastric tube daily for 8 weeks.

Other 40 rats were subjected to induction of Type2DM and hypertension: Type 2 diabetes was induced in the rats by fasting them overnight and then I.P. injection of nicotinamide solution
$(100 \mathrm{mg} / \mathrm{kg})$ followed by I.P. I of streptozotocin(STZ) solution $(60 \mathrm{mg} / \mathrm{kg}) 20 \mathrm{~min}$ later, then the rats were given glucose $5 \%$ in the drinking water for 24 hours to avoid hypoglyceamia ${ }^{(\mathbf{1 3})}$.. Previous reports showed that STZ injection produces not only diabetes mellitus, but also a significant elevation of blood pressure $^{(14)}$.

After one week, fasting blood glucose (FBG) levels and arterial blood pressure were measured and we selected rats which demonstrating moderate hyperglyceamia (145-221 $\mathrm{mg} / \mathrm{dl})$ and systemic hypertension ( MABP> $110 \mathrm{mmHg}$ )

The diabetic -hypertensive rats were divided into 4 groups as follows:

G2: diabetic-hypertensive control group: given daily oral distalled water for 8 weeks.

G3: Diabetic hypertensive group given gliclazide as a single dose of $5 \mathrm{mg} / \mathrm{kg} /$ day $/$ P.O. ${ }^{(15)}$

G4: Diabetic hypertensive group given nebivolol as a single dose of $10 \mathrm{mg} / \mathrm{kg} / \mathrm{day} / \mathrm{P}^{-O^{(16)}}$

G5: Diabetic hypertensive group given gliclazide and nebivolol at the same previous doses ${ }^{(15 \& 16)}$

After 8 weeks from administration of the drugs, the following parameters were estimated :

- $\quad$ Fasting blood glucose (FBG) level before and after induction of T2DM and then after 8 weeks treatment. The rats were deprived from food (fastened) for 12 hours at the night before measuring the FBG, using the Accu-Chek Active Blood Glucose Meter ${ }^{(\mathbf{1 7})}$.

- $\quad$ Arterial blood pressure:by using the non invasive blood pressure monitoring ${ }^{(\mathbf{1 4})}$ [NIBP-8 User s Manual (Ohio, USA)]

- After measurement of blood pressure, blood samples were collected from retrobulbar plexus for determination of serum insulin, nitric oxide(NO), superoxide dismutase (SOD), malondialdehyde (MDA) and lipid profile( total cholesterol(TC), triglyceride(TG) low density lipoprotein (LDL)and high density lipoprotein HDL) according to the method of the commercial kits.

-In vitro experiments: response of isolated aortic strips of the rats, of all groups, to noradrenaline(NA) before and after addition of acetylcholine(Ach) using a10 $\mathrm{ml}$ capacity organ path (Palmer, England) and Kreb's solution ${ }^{(\mathbf{1 8 , 1 9})}$.

\section{Procedure:}

After measurement of the arterial blood pressure rats were sacrificed by cutting the throat and the chest was opened. The aorta was cut as near the heart as possible and dissected free for long distance as possible. The aorta was cut spirally according to Furchgott ${ }^{(20)}$ to produce a 
continuous strip, about $4 \mathrm{~mm}$ wide and 3 to $4 \mathrm{~cm}$ long. A thread was attached at each end of the preparation. One end was attached to a fine glass tube through which passed oxygen and the other end was attached to a side lever writing on a slowly moving smoked drum.

The aortic strip was kept in $10 \mathrm{ml}$ capacity organ bath containing Krebs solution and the temperature of the medium was kept constant at $37^{\circ} \mathrm{C}$ by means of an electric thermostat (Biosience). The preparation was' then left in the bath for about 60 to $90 \mathrm{~min}$ to equilibrate after dissection.

\section{Experimental design in vitro:}

To study the response of isolated aortic strips to NA in treated and non treated groups, the experiment was conducted as follows:

After stabilization of the tissue, a cumulative concentration- response curve was recorded. The concentrations of NA used were $1,2,4,8,16,32,64,128 \mu \mathrm{g} / \mathrm{ml}$. After the last concentration $(128 \mu \mathrm{g} / \mathrm{ml})$ the preparation washed throughly until the original baseline was regained. These steps were repeated after putting single dose $(32 \mu \mathrm{g} / \mathrm{ml})$ of $\mathrm{Ach}^{(21)}$. The changes of response to NA in different groups were calculated as change in amplitude of NA-induced contraction in respect to that elicited in the control (non-diabetic) group.

\section{Statistical Analysis}

\section{Presentation of data of the results statistical analysis.}

The data of the obtained results were presented and tabulated as means \pm SE, then subjected to one-way ANOVA test followed by post Hoctest L.S.D test for determination of significance of difference between means by using SPSS statistical program version 14. Paired-t test used to compare the amplitude of contraction in response to NA before and after Ach .The means were significantly different when $\mathrm{P}<0.05^{(\mathbf{2 2})}$

\section{RESULTS}

G1: In control normal group the FBG was $86.8 \pm 3.6 \mathrm{mg} / \mathrm{dl}$, serum insulin level was $18.5 \pm 0.37 \mu \mathrm{u} / \mathrm{ml}$, MABP was $89.1 \pm 1.9 \mathrm{mmHg}$ ,serum MDA level was $2.2 \pm 0.14 \mathrm{mmol} / \mathrm{L}$, serum $\mathrm{NO}$ was $4.6 \pm 0.22 \mu \mathrm{mol} / \mathrm{ml}$ and lipid profile( TC, TG , LDL and HDL)were 50 $\pm 1.68,31.66 \pm 0.88$, $35.5 \pm 1.28$ and $21.3 \pm 1.05 \mathrm{mg} / \mathrm{dl}$ respectively. In control normal group NA in cumulative concentrations of $1,2,4,8,16,32,64,128 \mu \mathrm{g} / \mathrm{ml}$ ) produced a dose dependant increase in the contractility of rat aortic strip as shown in table 2 ( figre1).

Addition of (Ach) before the cumulative concentration of NA $(1-128 \mu \mathrm{g} / \mathrm{ml})$ produced significant $(\mathrm{P}<0.05)$ reduction of $\mathrm{NA}$ induced contraction The corresponding percent reduction was $33.5 \pm 1.58$ ( table 3 ).

G2: In diabetic -hypertensive control group(DH) there was a significant $(\mathrm{P}<0.05)$ increase in (FBG)in comparison with G1 (from $86 \pm 3.6 \mathrm{mg} / \mathrm{dl}$ to $189 \pm 5.59 \mathrm{mg} / \mathrm{dl}$ ), $\operatorname{MABP}$ ( from $89.1 \pm 1.94$ $\mathrm{mmHg}$ to $142.3 \pm 1.89 \mathrm{mmHg}$ ) serum MDA level(from $2.2 \pm 0.14$ to $4.3 \pm 0.19 \mathrm{mmol} / \mathrm{L}$ ) and some parameters in lipid profile(TC, TG and LDL) when compared with G1(table1).Furthermore, there was significant $(\mathrm{P}<0.05)$ decreases of plasma insulin level (from $18 \pm 0.37 \mu \mathrm{u} / \mathrm{ml}$ to $7.3 \pm 0.22 \mu \mathrm{u} / \mathrm{ml}$ ), serum $\mathrm{NO}$ (from4.6 \pm 0.22 to $1.7 \pm 0.1 \mu \mathrm{mol} / \mathrm{ml}$ ), activity of serum $\mathrm{SOD}$ (from $5.3 \pm 0.02 \quad$ to $1.48 \pm 0.13 \quad \mathrm{U} / \mathrm{ml}$ )and HDL(from $35.5 \pm 1.28$ to $21.8 \pm 1.35 \mathrm{mg} / \mathrm{dl}$ ) when compared with G1 (table1). The response of aortic strips to cumulative concentrations of NA in G2 was significantly $(\mathrm{P}<0.05)$ decreased the maximum contraction decreased from $30 \pm 0.085$ to17.5 $\pm 0.089 \mathrm{~mm}$ when compared with G1(table2, figure2). Addition of Ach before cumulative concentrations of NA did not produce significant decrease $(\mathrm{P}>0.05)$ of NA induced contraction the corresponding percent reduction was $12.7 \pm 0.81 \%$ (table3)

G3: (gliclazide treated group) showed significant $(\mathrm{P}<0.05)$ decrease in $\mathrm{FBG}$ level(from189 \pm 5.59 to1 $16.5 \pm 2.1 \mathrm{mg} / \mathrm{dl}$ ),MABP(from142.3 \pm 1.89 to124.8 $\pm 1.89 \mathrm{mmHg}$ ), serum MDA(from $4.3 \pm 0.19$ to $3.1 \pm 0.10 \mu \mathrm{m} / \mathrm{L}$ ), $\quad \mathrm{TC}, \mathrm{TG}$, and $\mathrm{LDL}$ (from $112.5 \pm 1.94, \quad 64.33 \pm 1.4$ and $55.5 \pm 1.08$ to $65.8 \pm 1.77, \quad 41.66 \pm 1.3$ and $35.1 \pm 1.66 \mathrm{mg} / \mathrm{dl}$ respectively) when compared with G2 (table 1). These values still significantly $(\mathrm{P}<0.05)$ higher than that of G1. Also gliclazide led to significant $(\mathrm{P}<0.05)$ increase in plasma insulin level( from $7 \pm 0.22$ to $13.4 \pm 0.39 \mu \mathrm{u} / \mathrm{ml})$, serum NO (from $1.7 \pm 0.1$ to $3.2 \pm 0.1 \mu \mathrm{mol} / \mathrm{ml}$ ), activity of serum SOD(from $1.48 \pm 0.13$ to $3.46 \pm 0.22 \mathrm{U} / \mathrm{ml}$ ) and HDL (from $21.8 \pm 1.35$ to $30.8 \pm 1.13 \mathrm{mg} / \mathrm{dl}$ ) when compared with G2. These values still significantly $(\mathrm{P}<0.05)$ lower than that of $\mathrm{G} 1$ (table $1)$.

In gliclazide treated group, the response of aortic strips to cumulative concentrations of NA was significantly $(\mathrm{P}<0.05)$ increased when compared with G2 (table 2), the maximum contraction increased from $17.5 \pm 0.089$ to $23 \pm 0.057 \mathrm{~mm}$. Addition of Ach before cumulative concentrations of NA produced significant decrease $(\mathrm{P}<0.05)$ of NA induced contraction, the maximum contraction was decreased from 23 0.057 to $18 \pm 0.11 \mathrm{~mm}$ (table2,figure 3 ). The corresponding percent reduction was 
$21.7 \pm 0.97 \%$ (table 3 ). The percent reduction of contraction was significantly $(\mathrm{P}<0.05)$ increased when compared with that of G2 $(12.7 \pm 0.81 \%)$, but still significantly lower than that of G1 $(33.5 \pm 1.58 \%)$ (table3, ).

G4: (nebivolol treated group) showed significant $(\mathrm{P}<0.05)$ decrease in FBG level (from $189 \pm 5.59$ to $130 \pm 3.1 \mathrm{mg} / \mathrm{dl}$ ), MABP (from $142.3 \pm 1.89$ to $85.4 \pm 1.53 \mathrm{mmHg}$ ), serum MDA (from $4.3 \pm 0.19$ to $2.7 \pm 0.23 \mu \mathrm{m} / \mathrm{L}$ ), TC, and LDL(from 112.5 \pm 1.94 and $55.5 \pm 1.08$ to $105.5 \pm 1.94$ and $50.5 \pm 1.5 \mathrm{mg} / \mathrm{dl}$ respectively) when compared with G2 (table 1). The values of MABP and MDA was not significantly different than that of G1, but these of FBG,TC and LDL still significantly $(\mathrm{P}<0.05)$ higher than that of G1. Furthermore nebivolol also led to significant $(\mathrm{P}<0.05)$ increase in plasma serum NO (from $1.7 \pm 0.1$ to $3.5 \pm 0.15 \mu \mathrm{mol} / \mathrm{ml}$ ), activity of serum SOD (from $1.48 \pm 0.13$ to $3.6 \pm 0.18 \mathrm{U} / \mathrm{ml}$ ) when compared with $\mathrm{G} 2$. These values still significantly $(\mathrm{P}<0.05)$ lower than that of G1(table 1). Nebivolol did not affect serum insulin, TG and HDL level when compared with G2(table1).

In nebivolol treated group, the response of aortic strips to cumulative concentrations of NA was significantly $(\mathrm{P}<0.05)$ increased when compared with G2(table 2), the maximum contraction increased from $17.5 \pm 0.089$ to $41 \pm 0.06 \mathrm{~mm}$. Addition of Ach before cumulative concentrations of NA produced significant decrease $(\mathrm{P}<0.05)$ of NA induced contraction, the maximum contraction was decreased from $41 \pm 0.06$ to $31 \pm 0.06 \mathrm{~mm}$ (table 2 figure 4). The corresponding percent reduction was $24.7 \pm 1.008 \%$. The reduction of contraction was significantly $(\mathrm{P}<0.05)$ increased when compared with that of $\mathrm{G} 2$ (from $12.7 \pm 0.818 \%$ to $24.7 \pm 1.008 \%$ ), but still significantly lower than that of G1 (33.5 $\pm 1.58 \%)$ (table 3)

G5: (glyclazide-nebivolol treated group) showed significant $(\mathrm{P}<0.05)$ decrease in FBG level (from $189 \pm 5.59$ to101.6 $\pm 1.1 \mathrm{mg} / \mathrm{dl}$ ), MABP (from $142.3 \pm 1.89$ to $88.1 \pm 2.04 \mathrm{mmHg}$ ), serum MDA (from $4.3 \pm 0.19$ to $2.35 \pm 0.16 \mu \mathrm{m} / \mathrm{L}$ ), total cholesterol, triglyceride and LDL (from $112.5 \pm 1.94,64.33 \pm 1.4$ and $55.5 \pm 1.08$ to $60.5 \pm 1.46$, $41.66 \pm 1.3$ and $29.1 .1 \pm 1.25 \mathrm{mg} / \mathrm{dl}$ respectively) when compared with G2(table 1). The values of MABP and MDA was not significantly different than that of G1, but these of FBG, TC and LDL still significantly $(\mathrm{P}<0.05)$ higher than that ofG1. Also this group showed significant $(\mathrm{P}<0.05)$ increase in plasma insulin level (from $7 \pm 0.22$ to $13.4 \pm 0.38 \mu \mathrm{u} / \mathrm{ml}$ ), serum NO (from $1.7 \pm 0.1$ to $4 \pm 0.14 \mu \mathrm{mol} / \mathrm{ml}$ ), activity of serum SOD (from $1.48 \pm 0.13$ to $4.36 \pm 0.19 \mathrm{U} / \mathrm{ml}$ ) and HDL (from $21.8 \pm 1.35$ to $31.8 \pm 1.3 \mathrm{mg} / \mathrm{dl}$ ) when compared withG2. These values still significantly $(\mathrm{P}<0.05)$ lower than that of control normal G1(table 1). In G5 the values of FBG, MABP and MDA were significantly $(\mathrm{P}<0.05)$ lower when compared with that of G3 and the values of NO and SOD were significantly $(\mathrm{P}<0.05)$ higher when compared with that of G3, while the values of insulin and lipid profile were not significantly different than that in G3 (table1).

In G5, the response of aortic strips to cumulative concentrations of NA was significantly $(\mathrm{P}<0.05)$ increased when compared with G2(table 2), the maximum contraction increased from $17.5 \pm 0.089$ to $39 \pm 0.066 \mathrm{~mm}$. Addition of Ach before cumulative concentrations of NA produced significant decrease $(\mathrm{P}<0.05)$ of NA induced contraction, the maximum contraction was decreased from $39 \pm$ 0.066 to $25 \pm 0.0 .044 \mathrm{~mm}$ (table2, figure5). The corresponding percent reduction was $35.15 \pm 1.93 \%$. The percent reduction of contraction was significantly $(\mathrm{P}<0.05)$ increased when compared with that of $\mathrm{G} 2(12.7 \pm 0.818 \%)$, and there was no significant difference when compared with that of G1(33.5 $\pm 1.58 \%$ ) (table 3$)$. The reduction of contraction in G5 was significantly $(\mathrm{P}<0.05)$ higher than that in G3 and G4(table 3) 
Table (1): $\quad$ Effect (means \pm SE) of gliclazide $(5 \mathrm{mg} / \mathrm{kg} /$ day), nebivolol $10 \mathrm{mg} / \mathrm{kg}$ and gliclazide with nebivolol (GN) on fasting blood glucose (FBG), mean arterial blood pressure (MABP), serum insulin superoxide dismutase (SOD), malondialdehyde (MDA), nitric oxide (NO) and lipid profile total cholesterol (TC), triglyceride (TG),low density lipoprotein (LDL), high density lipoprotein HDL in experimentallyinduced diabetic hypertensive rats. n:6

\begin{tabular}{|c|c|c|c|c|c|}
\hline Parameters & $\begin{array}{c}\text { Control } \\
\text { normal } \\
\text { G1 }\end{array}$ & $\begin{array}{c}\text { Diabetic } \\
\text { hypertensive } \\
\text { G2 }\end{array}$ & $\begin{array}{c}\text { Gliclazide } \\
\text { G3 }\end{array}$ & $\begin{array}{c}\text { Nebivolol } \\
\text { G4 }\end{array}$ & $\begin{array}{c}\text { Gliclazide+ } \\
\text { Nebivolol } \\
\text { G5 }\end{array}$ \\
\hline \multirow[t]{2}{*}{$\overline{\mathrm{FBG}(\mathrm{mg} / \mathrm{dl})}$} & $86.8^{\mathrm{A}}$ & $189^{\mathrm{B}}$ & $116.5^{\mathrm{C}}$ & $130^{\mathrm{D}}$ & $101.6^{\mathrm{E}}$ \\
\hline & \pm 3.6 & \pm 5.59 & \pm 2.1 & \pm 3.1 & \pm 1.1 \\
\hline \multirow[t]{2}{*}{$\overline{\text { Serum insulin level }(\mu \mathrm{U} / \mathrm{ml})}$} & $18^{\mathrm{A}}$ & $7.3^{\mathrm{B}}$ & $13.4^{\mathrm{C}}$ & $8.1^{\mathrm{B}}$ & $13.4^{\mathrm{C}}$ \\
\hline & \pm 0.37 & \pm 0.22 & \pm 0.39 & \pm 0.33 & \pm 0.38 \\
\hline \multirow[t]{2}{*}{$\overline{\mathrm{MABP}(\mathrm{mmHg})}$} & $89.1^{\mathrm{A}}$ & $142.3^{\mathrm{B}}$ & $124.8^{C}$ & $85.4^{\mathrm{A}}$ & $88.1^{\mathrm{A}}$ \\
\hline & \pm 1.94 & \pm 1.89 & \pm 1.89 & \pm 1.53 & \pm 2.04 \\
\hline \multirow[t]{2}{*}{ NO level $\mu \mathrm{mol} / \mathrm{ml}$} & $4.6^{\mathrm{A}}$ & $1.7^{\mathrm{B}}$ & $3.2^{\mathrm{C}}$ & $3.5^{\mathrm{C}}$ & $4^{\mathrm{D}}$ \\
\hline & \pm 0.22 & \pm 0.1 & \pm 0.1 & \pm 0.15 & \pm 0.14 \\
\hline \multirow[t]{2}{*}{$\overline{\mathrm{MDA}} \mathrm{mmol} / \mathrm{L}$} & $2.2^{\mathrm{A}}$ & $4.3^{\mathrm{B}}$ & $3.1^{\mathrm{C}}$ & $2.7^{\mathrm{CA}}$ & $2.35^{\mathrm{A}}$ \\
\hline & \pm 0.14 & \pm 0.19 & \pm 0.10 & \pm 0.23 & \pm 0.16 \\
\hline \multirow[t]{2}{*}{$\overline{\mathrm{SOD} U / \mathrm{ml}}$} & $5.3^{\mathrm{A}}$ & $1.48^{\mathrm{B}}$ & $3.46^{\mathrm{C}}$ & $3.6^{\mathrm{C}}$ & $4.36^{\mathrm{D}}$ \\
\hline & \pm 0.02 & \pm 0.13 & \pm 0.22 & \pm 0.18 & \pm 0.19 \\
\hline \multicolumn{6}{|l|}{ Lipid profile (mg/dl) } \\
\hline \multirow[t]{2}{*}{ TC } & $50^{\mathrm{A}}$ & $112.5^{\mathrm{B}}$ & $65.8^{\mathrm{C}}$ & $105.5^{\mathrm{D}}$ & $60.5^{\mathrm{C}}$ \\
\hline & \pm 1.68 & \pm 1.94 & \pm 1.77 & \pm 1.94 & \pm 1.46 \\
\hline \multirow[t]{2}{*}{$\overline{\mathrm{TG}}$} & $31.66^{\mathrm{A}}$ & $64.33^{\mathrm{B}}$ & $41.66^{C}$ & $60.8^{\mathrm{B}}$ & $41^{\mathrm{C}}$ \\
\hline & \pm 0.88 & \pm 1.4 & \pm 1.3 & \pm 1.16 & \pm 1.07 \\
\hline \multirow[t]{2}{*}{$\overline{\mathrm{HDL}}$} & $35.5^{\mathrm{A}}$ & $21.8^{\mathrm{B}}$ & $30.8^{\mathrm{C}}$ & $21.5^{\mathrm{B}}$ & $31^{\mathrm{C}}$ \\
\hline & \pm 1.28 & \pm 1.35 & \pm 1.13 & \pm 0.88 & \pm 1.3 \\
\hline \multirow[t]{2}{*}{$\overline{\mathrm{LDL}}$} & $21.3^{\mathrm{A}}$ & $55.5^{\mathrm{B}}$ & $35.1^{\mathrm{C}}$ & $50.5^{\mathrm{D}}$ & $29.1^{\mathrm{C}}$ \\
\hline & \pm 1.05 & \pm 1.08 & \pm 1.66 & \pm 1.5 & \pm 1.25 \\
\hline
\end{tabular}

Within the same row means with different common superscript capital letters are significantly different $(\mathrm{p}<$ 0.05).n: number of rats in each group. 
Table (2): Effect (means \pm SE) of gliclazide $5 \mathrm{mg} / \mathrm{kg} / \mathrm{day}$, nebivolol $10 \mathrm{mg} / \mathrm{kg} / \mathrm{day}$ and gliclazide with nebivolol on the response of isolated aortic strips to noradrinaline (NA) before and after actylcholine (Ach).n:6

\begin{tabular}{|c|c|c|c|c|c|c|c|c|c|c|}
\hline \multirow[b]{2}{*}{$\begin{array}{l}\text { Concentrations } \\
\text { of NA }\end{array}$} & \multicolumn{2}{|c|}{$\begin{array}{l}\text { Control normal } \\
\text { G1 }\end{array}$} & \multicolumn{2}{|c|}{$\begin{array}{c}\text { Diabetic } \\
\text { hypertensive }(\mathrm{G} 2)\end{array}$} & \multicolumn{2}{|c|}{$\begin{array}{l}\text { Gliclazide } \\
\text { G3 }\end{array}$} & \multicolumn{2}{|c|}{$\begin{array}{l}\text { Nebivolol } \\
\quad \text { G3 }\end{array}$} & \multicolumn{2}{|c|}{$\begin{array}{l}\text { Gliclazide } \\
+ \text { Nebivolol } \\
\text { G5 }\end{array}$} \\
\hline & $\mathrm{NA}$ & $\begin{array}{c}\text { Ach }+ \\
\text { NA }\end{array}$ & $\mathrm{NA}$ & $\mathrm{Ach}+\mathrm{NA}$ & NA & $\begin{array}{c}\text { Ach }+ \\
\text { NA }\end{array}$ & NA & $\begin{array}{c}\text { Ach + } \\
\text { NA }\end{array}$ & NA & $\mathrm{Ach}+\mathrm{NA}$ \\
\hline \multirow[t]{2}{*}{1} & $12^{\mathrm{A}}$ & $3.8^{\mathrm{B}}$ & $4.5^{\mathrm{A}}$ & $3.8^{\mathrm{A}}$ & $\overline{9^{\mathrm{A}}}$ & $5^{\mathrm{B}}$ & $11^{\mathrm{A}}$ & $8^{\mathrm{B}}$ & $11^{\mathrm{A}}$ & $9^{\mathrm{B}}$ \\
\hline & \pm 0.096 & \pm 0.06 & \pm 0.07 & \pm 0.07 & \pm 0.079 & \pm 0.09 & \pm 0.096 & \pm 0.96 & \pm 0.076 & \pm 0.057 \\
\hline \multirow[t]{2}{*}{2} & $16^{\mathrm{A}}$ & $8^{\mathrm{B}}$ & $\overline{7^{A}}$ & $\overline{6^{\mathrm{A}}}$ & $12^{\mathrm{A}}$ & $7.5^{\mathrm{B}}$ & $19^{\mathrm{A}}$ & $15^{\mathrm{B}}$ & $17^{\mathrm{A}}$ & $14^{\mathrm{B}}$ \\
\hline & \pm 0.057 & \pm 0.04 & \pm 0.073 & \pm 0.05 & \pm 0.079 & \pm 0.1 & 0.09 & \pm 0.085 & \pm 0.068 & \pm 0.057 \\
\hline \multirow[t]{2}{*}{4} & $19^{\mathrm{A}}$ & $11^{\mathrm{B}}$ & $\overline{9^{A}}$ & $8.33^{\mathrm{A}}$ & $15^{\mathrm{A}}$ & $11^{\mathrm{B}}$ & $27^{\mathrm{A}}$ & $21^{\mathrm{B}}$ & $24^{\mathrm{A}}$ & $18^{\mathrm{B}}$ \\
\hline & \pm 0.087 & \pm 0.047 & \pm 0.071 & \pm 0.066 & \pm 0.071 & \pm 0.11 & \pm 0.079 & \pm 0.11 & \pm 0.049 & \pm 0.06 \\
\hline \multirow[t]{2}{*}{8} & $22^{\mathrm{A}}$ & $14^{\mathrm{B}}$ & $11^{\mathrm{A}}$ & $10^{\mathrm{A}}$ & $19^{\mathrm{A}}$ & $15^{\mathrm{B}}$ & $35^{\mathrm{A}}$ & $25^{\mathrm{B}}$ & $32^{\mathrm{A}}$ & $21^{\mathrm{B}}$ \\
\hline & \pm 0.087 & \pm 0.033 & 0.088 & \pm 0.042 & \pm 0.071 & \pm 0.12 & \pm 0.07 & \pm 0.092 & \pm 0.065 & \pm 0.047 \\
\hline \multirow[t]{2}{*}{16} & $25^{\mathrm{A}}$ & $16^{\mathrm{B}}$ & $13^{\mathrm{A}}$ & $13^{\mathrm{A}}$ & $\overline{21^{\mathrm{A}}}$ & $16.5^{\mathrm{B}}$ & $39^{\mathrm{A}}$ & $27^{\mathrm{B}}$ & $36^{\mathrm{A}}$ & $23^{\mathrm{B}}$ \\
\hline & \pm 0.1 & \pm 0.04 & \pm 0.08 & \pm 0.06 & \pm 0.057 & \pm 0.12 & \pm 0.06 & \pm 0.092 & \pm 0.076 & \pm 0.047 \\
\hline \multirow[t]{2}{*}{32} & $28^{\mathrm{A}}$ & $18^{\mathrm{B}}$ & $15^{\mathrm{A}}$ & $\overline{14^{\mathrm{A}}}$ & $22^{\mathrm{A}}$ & $17.5^{\mathrm{B}}$ & $40^{\mathrm{A}}$ & $29^{\mathrm{B}}$ & $38^{\mathrm{A}}$ & $24^{\mathrm{B}}$ \\
\hline & \pm 0.096 & \pm 0.049 & \pm 0.084 & \pm 0.063 & \pm 0.057 & \pm 0.11 & \pm 0.06 & \pm 0.095 & \pm 0.067 & \pm 0.047 \\
\hline \multirow[t]{2}{*}{64} & $30^{\mathrm{A}}$ & $20^{B}$ & $17^{\mathrm{A}}$ & $15.5^{\mathrm{A}}$ & $23^{\mathrm{A}}$ & $18^{\mathrm{B}}$ & $41^{\mathrm{A}}$ & $31^{B}$ & $39^{\mathrm{A}}$ & $25^{\mathrm{B}}$ \\
\hline & \pm 0.085 & \pm 0.057 & \pm 0.098 & \pm 0.063 & \pm 0.057 & \pm 0.11 & \pm 0.06 & \pm 0.095 & \pm 0.066 & \pm 0.047 \\
\hline \multirow[t]{2}{*}{128} & $30^{\mathrm{A}}$ & $20^{\mathrm{B}}$ & $17^{\mathrm{A}}$ & $15.5^{\mathrm{A}}$ & $23^{\mathrm{A}}$ & $18^{\mathrm{B}}$ & $\overline{41^{\mathrm{A}}}$ & $31^{\mathrm{B}}$ & $39^{\mathrm{A}}$ & $25^{\mathrm{B}}$ \\
\hline & \pm 0.089 & \pm 0.057 & \pm 0.098 & \pm 0.063 & \pm 0.057 & \pm 0.11 & \pm 0.06 & \pm 0.06 & \pm 0.066 & \pm 0.047 \\
\hline
\end{tabular}

In the same row within the same group means with different superscript capital letters are significantly different $(\mathrm{p}<0.05)$

.n: number of experiment in each group.

Table 3: Percent reduction(means \pm SE) in maximum noradrenaline (NA) induced contraction of aortic strips of the rats of each group.

\begin{tabular}{llllll}
$\begin{array}{l}\text { Group } \\
\begin{array}{l}\text { Percent } \\
\text { reduction }\end{array}\end{array}$ & $\begin{array}{l}\text { Control } \\
\text { normal } \\
\text { G1 }\end{array}$ & $\begin{array}{l}\text { Diabetic } \\
\text { hypertevsine } \\
\text { G2 }\end{array}$ & Gliclazide & $\begin{array}{l}\text { Nebivolol } \\
\text { G4 }\end{array}$ & $\begin{array}{l}\text { Gliclazide+ } \\
\text { Nebivolol } \\
\text { G5 }\end{array}$ \\
\hline \%reduction in & $33.5 \%^{\mathrm{A}}$ & $12.76 \%^{\mathrm{B}}$ & $21.33 \%^{\mathrm{C}}$ & $24.7 \%^{\mathrm{C}}$ & \multicolumn{2}{|c}{$35.08 \%^{\mathrm{A}}$} \\
maximum & \pm 1.58 & \pm 0.81 & \pm 0.79 & \pm 1 & \pm 1.93 \\
contraction & & & & &
\end{tabular}

Within the same row means with different superscript capital letters are significantly different $(\mathrm{p}<0.05)$. 


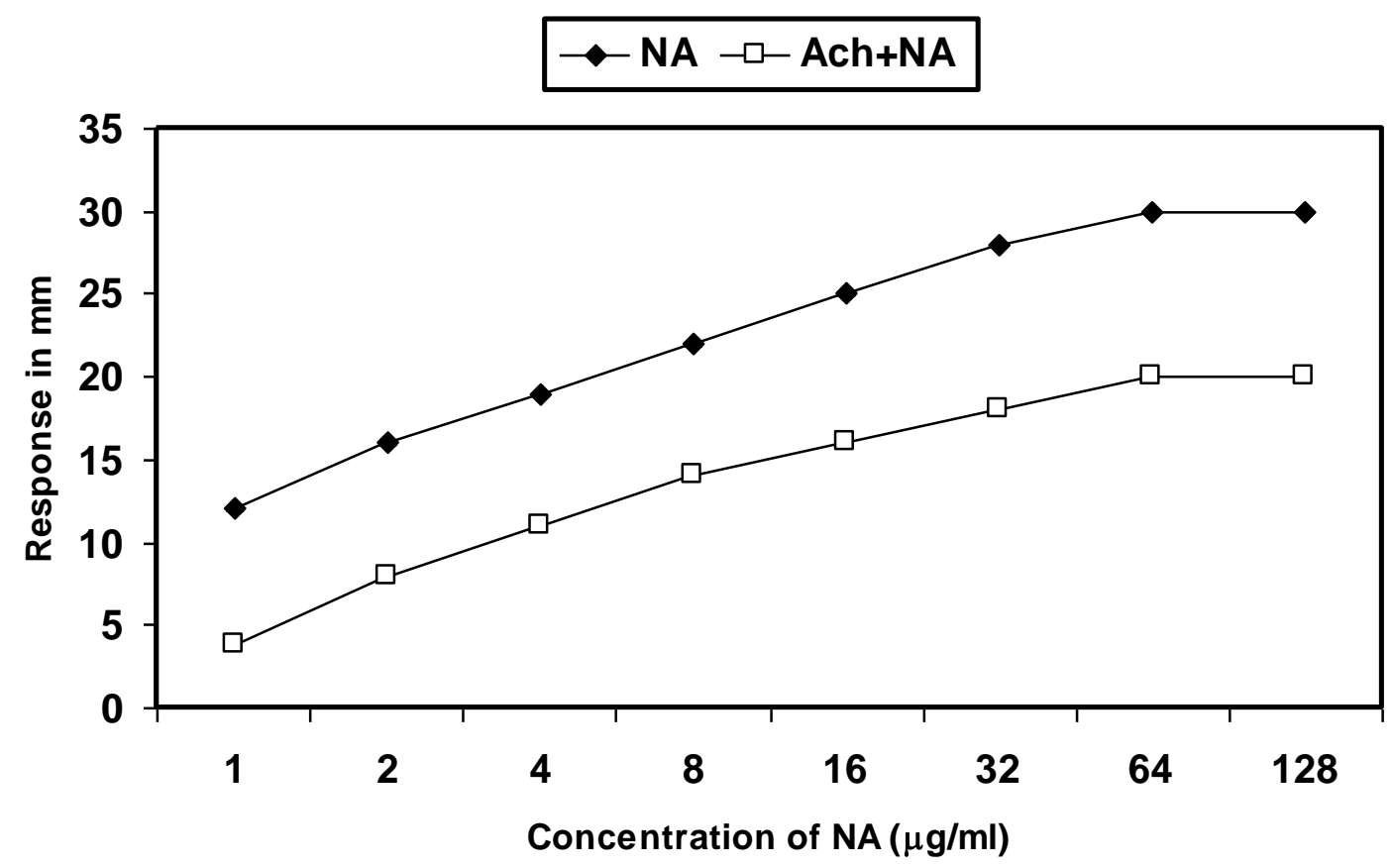

Fig. ( 1 ): $\quad$ Response of isolated rat's aortic strips to NA before and after addition of Ach in control normal group (G1).

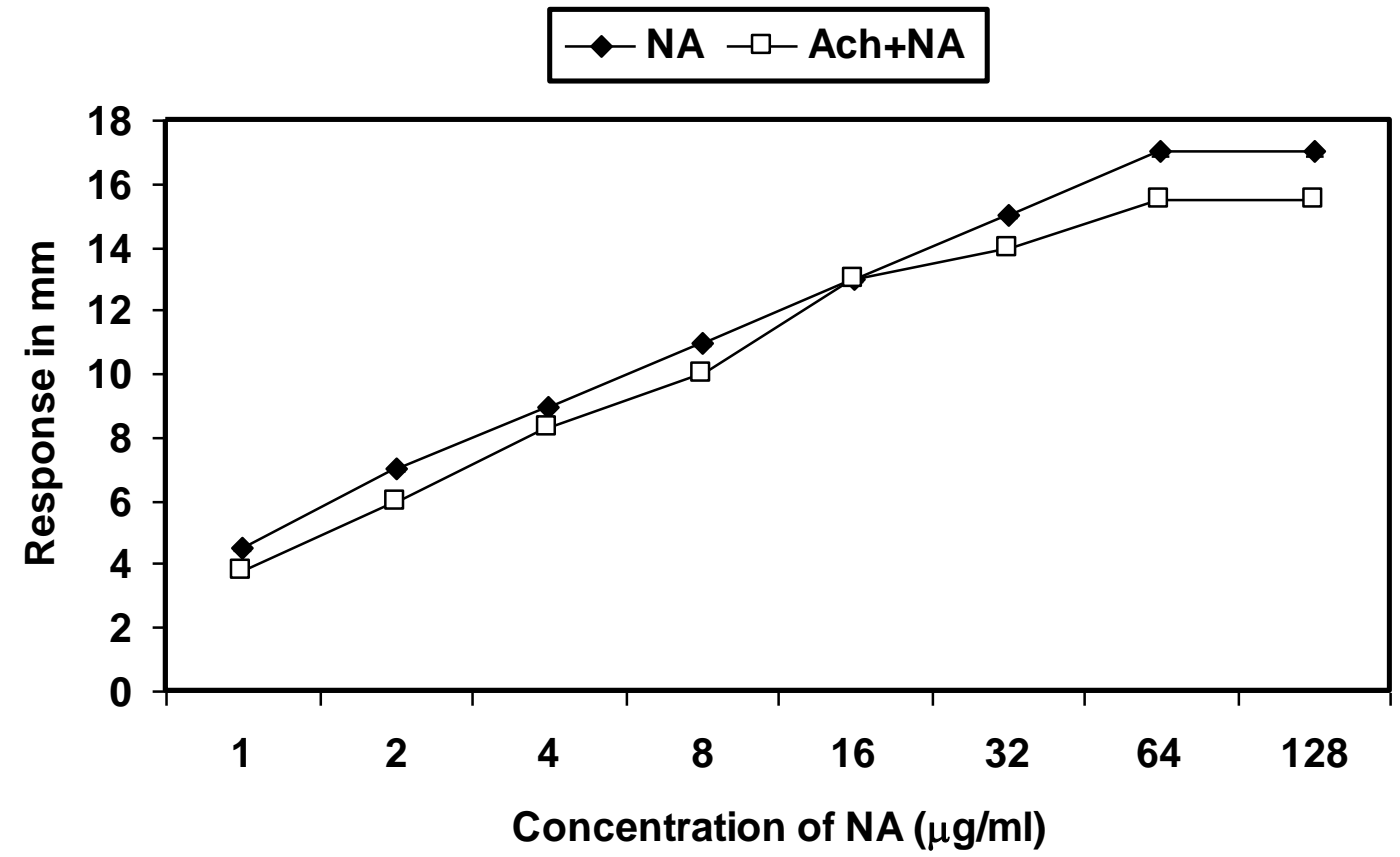

Fig. ( 2 ): $\quad$ Response of isolated rat's aortic strips to NA before and after addition of Ach in diabetic hypertensive group ( G2). 


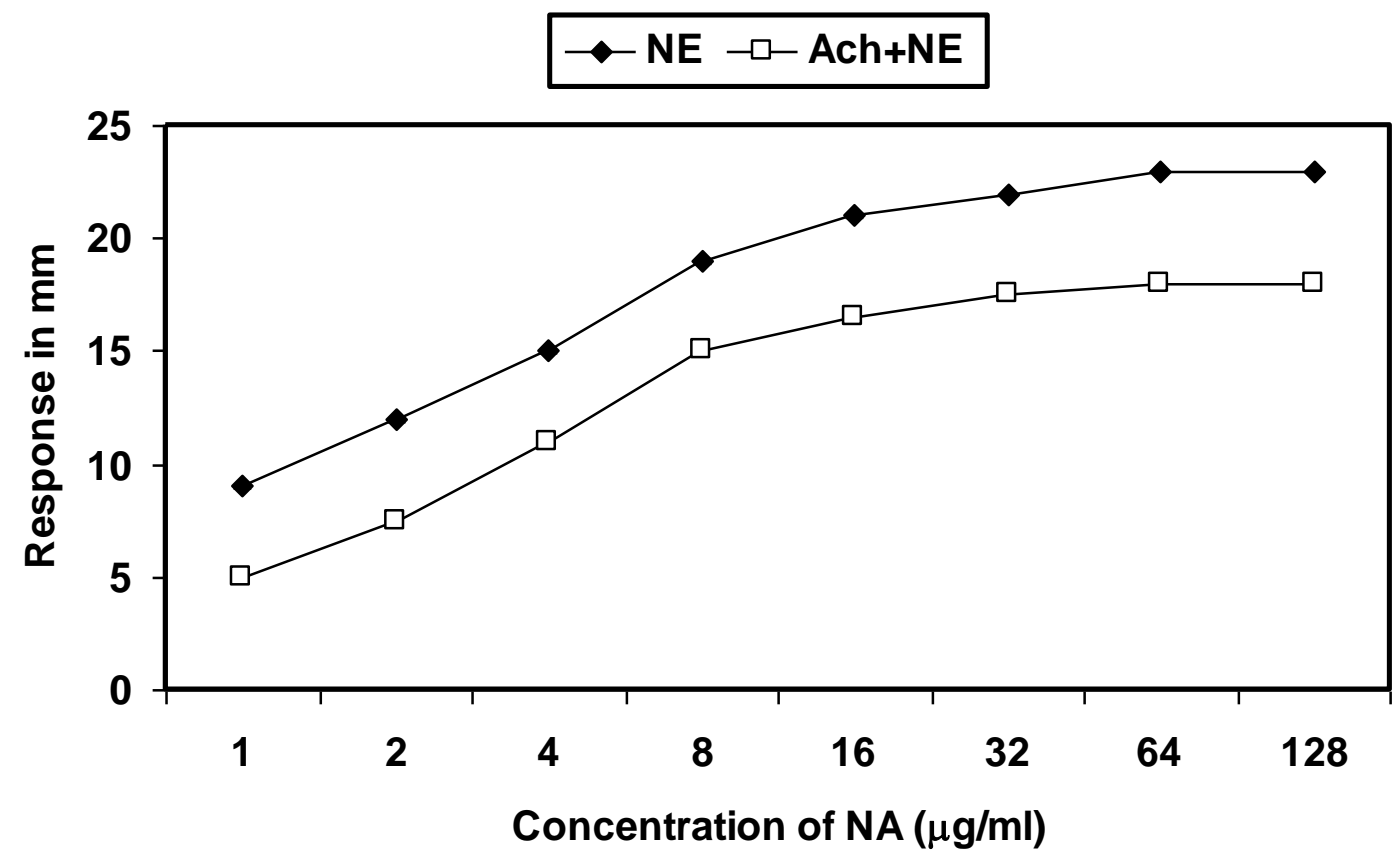

Fig. ( 3 ): $\quad$ Response of isolated rat's aortic strips to NA before and after addition of Ach in gliclazide treated group $(\mathrm{G} 3)$.

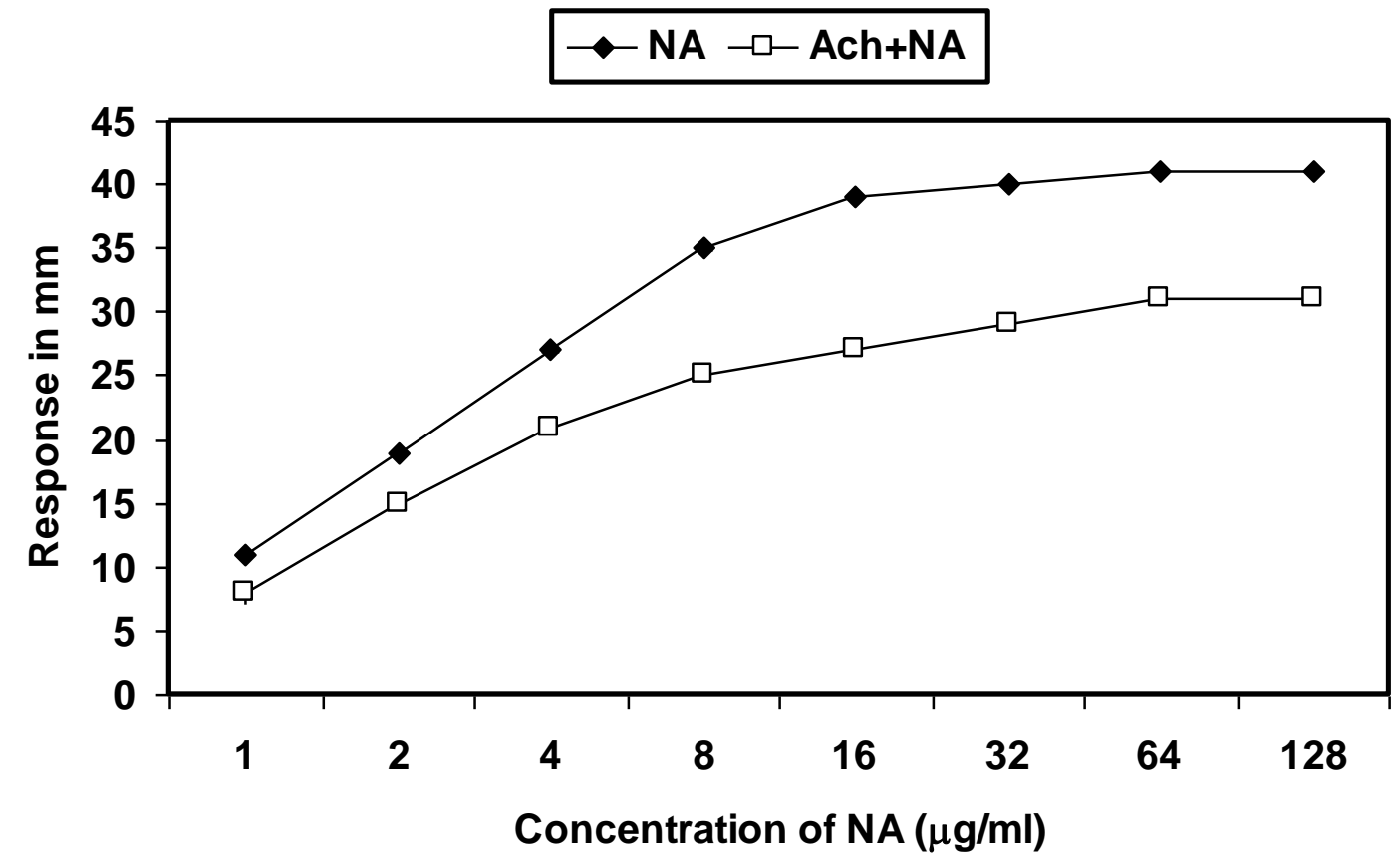

Fig. ( 4 ): $\quad$ Response of isolated rat's aortic strips to NA before and after addition of Ach in nebivolol treated group $(\mathrm{G} 4)$. 


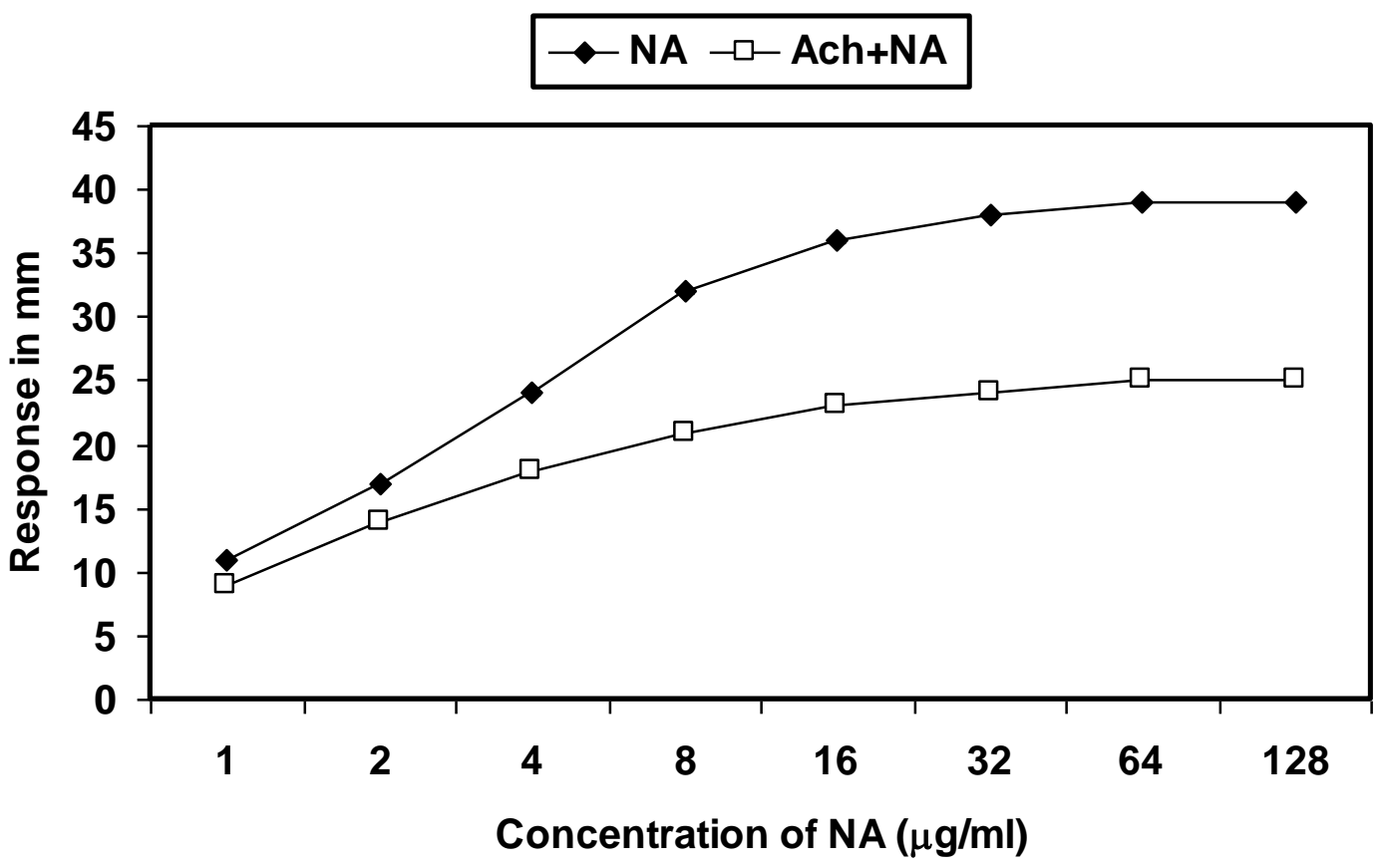

Fig. (5): Response of isolated rat's aortic strips to NA before and after addition of Ach in gliclazide +nebivolol treated group (G5).

\section{DISCUSSION}

Induction of type 2 diabetes mellitus in rats in the present study was carried out by intraperitoneal injection of partial protective dose of nicotinamide followed by I.P.I. of streptozotocin (STZ). This method is characterized by $40 \%$ reduction in B-cell mass resulting in moderate and stable hyperglycemia, glucose intolerance, ability of B-cell to respond to glucose altered but still present and preserve responsiveness to sulfonylureas ${ }^{(23)}$, , previous reports showed that injection of STZ, in rats, produced, not only, diabetes mellitus, but also, a significant elevation of blood pressure ${ }^{(\mathbf{1 4})}$.

In diabetic-hypertensive non treated group, There was increase in oxidative stress (increase MDA and decrease of SOD activity), decrease of $\mathrm{NO}$ and decrease in $\mathrm{NO}$ dependant vascular relaxation. All these results attributed to that diabetes is a state of increased oxidant stress $^{(24)}$.

Oxidative stress can be defined as a state of imbalance toward the factors that generate reactive oxygen radicals (superoxide or hydroxyl radicals) and away from the factors that protect cellular macromolecules from these reactants including antioxidants like superoxide dismutases, catalase, and glutathione peroxidases ${ }^{(25)}$. Mitochondria are thought to be the source of most cellular ROS, specifically superoxide radicals. Increased oxidative stress and excess ROS production (or reduced ROS regulation)lead to increase lipid peroxidation( increase malondialehyde MDA) can severely impair the cell and lead to macromolecular damage, dysfunction, and death ${ }^{(26)}$.

Diabetes can increase oxidative stress by several mechanisms including chronic hyperglycemia which leads to alteration of mitochondrial respiratory chain activity which leads to formation of surplus amount of hydroxyl radical $^{(27)}$. Also glucose autoxidation and nonenzymatic protein glycosylation are the main sources of this free radicals generation which lead to tissue damage and diabetic complications ${ }^{(28)}$. Also advanced glycation end-products (AGE),which progressively accumulate in diabetes, can generate free radicals ${ }^{(24)}$, Matute et al. ${ }^{(25)}$ reported that, antioxidants including glutathione, vitamin $\mathrm{E}$, vit. $\mathrm{C}$, superoxide dismutase and carotenoids have been reduced in diabetic patients .

In our study, diabetic hypertensive non treated group, showed a decrease in serum NO and the NO dependent vasorelaxation .In diabetes mellitus (DM) and hypertension, there is impairment of endothelial cell function which results from decrease of NO release and increase vasoconstrictor substances such as ROS, endothelin-1, angiotensin (ANG)II ,in addition insulin causes vasodilation by increasing vascular NO production through activation of NO synthase (NOS) but, this pathway is defective in type $2 \mathrm{DM}$ Furthermore divalent cation metabolism in vascular tissue is altered in patients with DM leading to depletion of free $\mathrm{Ca}^{2+} \& \mathrm{Mg}^{2+}$ and these 
changes decrease NO synthesis ${ }^{(\mathbf{6})}$. In addition increase oxidative stress and increase ROS in type $2 \mathrm{DM}$ lead to rapid inactivation of $\mathrm{NO}$ by oxidation to nitrite or nitrate ${ }^{(5)}$. Increase ROS not only increases degradation of $\mathrm{NO}$ but also decreases its biosynthesis ${ }^{(29)}$.

Type 2 DM and hypertension are associated with atherogenic dyslipidaemia which presents as an increase in plasma triglycerides, a reduction in high density lipoproteins (HDL)cholesterol and presence of small, dense lowdensity lipoprotein (LDL) particles ${ }^{(29)}$. Since insulin inhibits the hormone sensitive lipase, in diabetics, enhanced activity of this enzyme increases lipolysis and releases more free fatty acids into the circulation.

In the present study, we found that treatment of diabetic hypertensive rats with gliclazide for 8 weeks lead to highly significant decrease of fasting blood glucose (FBG). In addition, the plasma insulin level increased by highly significant manner. Similar results were obtained by Sivakumar and Subramanian ${ }^{(27)}$ who reported that administration of gliclazide 5 $\mathrm{mg} / \mathrm{kg} /$ day for 30 days in diabetic rats decreased blood glucose level and increased plasma insulin.

The mechanism by which gliclazide decreases blood glucose level and increases plasma insulin level is inhibition of ATP sensitive potassium $\left(\mathrm{K}^{+}\right)$channels in pancreatic B-cells which lead to depolarization and opening of voltage dependent $\mathrm{Ca}^{2+}$ channels and release of insulin. Also gliclazide increases insulin sensitivity and potentiates the suppression of hepatic glucose production in diabetic patients, furthermore, gliclazide may be effective in protection of $\mathrm{B}$ cells from the toxic action of reactive oxygen species in diabetes by its antioxidant effect ${ }^{(9)}$.

This study revealed that treatment with gliclazide also decreased MDA and increased SOD activity and NO when compared with diabetic hypertensive non treated group and, also, it improved NO mediated vascular relaxation. These results were in agreement with that obtained by Chen et al. ${ }^{(10)}$ who reported that gliclazide treatment, with a dose of $30-90 \mathrm{mg} / \mathrm{kg}$ for 12 weeks, of diabetic patients led to decrease of oxidative stress ( $\downarrow$ MDA \& $\uparrow$ SOD activity), increase of NO, and improvement of NO dependent vascular relaxation.

In DM, there is an increase in oxidative stress and decrease in antioxidant activity and impairment of NO dependant vascular relaxation due to decrease of NO bioavilability. This endothelial dysfunction is a pivotal determinant of atherosclerosis and diabetic vasculopathy ${ }^{(30)}$.

Gliclazide has antioxidant effect which results from the azabicyclooctyl ring, which is not found in other sulfonylureas, thus gliclazide can reduce the generation of ROS and peroxynitite, so it prevents the inactivation of $\mathrm{NO}$ and increases its biavailability, thus it protects aganist endothelial dysfunction (10)

.Also, gliclazide decreases monocyte adhesion to endothelium ,inhibits high glucosemediated neutrophil-endothelial cell adhesion and expression of endothelial adhesion molecules( all these mechanisms through inhibition of a protein kinase pathway), in addition, gliclazide reduces hypercoagulibility in type 2 diabetic patients by reduction of platelet over activity ${ }^{(\mathbf{3 1})}$.

Gliclazide treatment in our study led ,also, to improvement of lipid profile(TC,TG,LDL,HDL) ,these result in accordance with results obtained by Chen et al. ${ }^{(\mathbf{1 0})}$ who used $5 \mathrm{mg} / \mathrm{kg}$ of gliclazide for 12 weeks in newly diagnosed diabetic patients. Also, our results are in agreement with that Saravanan and Poinmurugan ${ }^{(32)}$ who administrated gliclazide 5 $\mathrm{mg} / \mathrm{kg} / \mathrm{d}$ for 45 days in STZ induced diabetic rats and reported that gliclazide improved serum, liver and kidney lipids content.

Insulin inhibits the hormone sensitive lipase, enhanced activity of this enzyme in diabetics ,leads to increase of lipolysis and release of more free fatty acids into the circulation, so treatment with gliclazide increases insulin release, and insulin sensitivity, leading to decrease in the synthesis of cholesterol and fatty acids ${ }^{(32)}$.

In the present study, also, we found that the treatment of diabetic hypertensive rats with gliclazide led to significant reduction of mean arterial blood pressure. This result can be explained by that, good control of blood glucose level improves macrovascular events and reduces the occurrence of these complications, also, we can suggest that, it may be partiely due to antioxidant properties of gliclazide which increases NO bioavailability, and has antiatherogenic effect ${ }^{(33)}$.

$\mathrm{DM}$ is common in patients with hypertension and greatly it increases the risk of cardiovascular diseases, including myocardial infarction, stroke and peripheral vascular diseases. The pharmacological treatment of patients with hypertension and DM has been surrounded by controversy because of concerns about the metabolic effect of several antihypertensive agents ${ }^{(\mathbf{1 2})}$. In our study, we tested, also, the effect of nebivolol on many metabolic parameters in 
diabetic hypertensive rats to see whether it improves or worsen these parameter and also to see interactions between it and gliclazide

In our study oral administration of nebivolol, a selective $B_{1}$ blocker, in diabetic hypertensive rats led to a significant reduction of blood glucose level without significant changes in insulin level. It also led to significant decrease in oxidative stress ( $\uparrow$ SOD activity, $\downarrow$ MDA level) ,increase serum NO and increase NO dependent vasorelaxation (vascular reactivity).

Effect of nebivolol on blood glucose and insulin level were in agreement with Manrique et al. ${ }^{(34)}$. They showed that nebivolol by dose of 10 $\mathrm{mg} / \mathrm{kg}$ for 21 days (3 weeks) improved blood glucose level in rat model manifested excess oxidative stress, and whole-body insulin resistance. The effect of nebivolol on oxidative stress was in agreement with Uzara et al. ${ }^{(35)}$ who reported that nebivolol has a potent antioxidant effect.

Styskal et al. ${ }^{26}$ reported that DM and hypertension are associated with increased oxidative stress which contributes to a decrease in insulin metabolic signaling in various insulin responsive tissues, ROS also rapidly inactivate, diminished the bioavailability of NO through conversion of locally released NO to peroxynitrite $\left(\mathrm{ONOO}^{-}\right)^{(\mathbf{2 6})}$. This effect contributes to microvascular dysfunction that results in decreased delivery of insulin and glucose to skeletal muscle tissue and other insulin-sensitive tissues, resulting in decreased insulin-mediated glucose transport so ,therapeutic strategies that inhibit or decrease oxidant stress have been shown to improve insulin sensitivity in hypertensive diabetic states ${ }^{(36)}$.

Nebivolol alone or with gliclazide showed improved oxidant stress by direct reduction of ROS which produces by NADPH oxidase system ,also it increases NO through stimulation of endothelial NO synthase (eNO) and increases its gene expression, furthermore, its antioxidant effect decreases rapid inactivation of $\mathrm{NO}$ and increases NO bioavailability, so ,nebivolol increases systemic insulin sensitivity, likely through reduction of NADPH oxidase activity and enhancement of endothelial NO synthase activity $^{(37)}$.

In our study ,also, nebivolol led to increase in NO dependent vasorelaxation, and decreased blood pressure to normal values in diabetic hypertensive rats. These results were in agreement with Georgescu et al. ${ }^{(16)}$ who administrated nebivolol by a dose of $10 \mathrm{mg} / \mathrm{kg}$ for 2 months and reported that nebivolol prevented and restored the endothelial dysfunction associated with DM , increased serum NO, and decreased blood pressure. The antihypertensive effect of nebivolol was attributed to endotheliumderived NO which increased by nebivolol as mentioned before ${ }^{(38)}$. NO lead to vasorelaxation of vascular smooth muscle through increase intracellular cyclic-GMP, furthermore NO has a number of intracellular effects that lead to vascular relaxation and prevent endothelial dysfunction development including, endothelial regeneration, reduction of oxidation-sensitive mechanisms, inhibition of leukocyte chemotaxis and platelets aggregation, and inhibition of vascular smooth muscle proliferation ${ }^{(\mathbf{3 9})}$.

In our study, nebivolol also led to significant decrease of total cholesterol and LDL.These results in accordance with Agrawal et al. ${ }^{(40)}$ who administrated nebivolol to hypertensive hyperlipidemic patients for average 59 days and reported that nebivolol improved lipid profile, they reported that this effect of nebivolol may be due to increase endothelial NO release, and blood pressure lowering effect .we suggest that this effect may be due to increasing insulin sensitivity which caused by nebivolol treatment.

We can conclude that, co-administration of gliclazide with nebivolol ,in this study has ,more or less, additive effect on the estimated metabolic and cardiovascular parameters and not antagonis each other

\section{REFERENCES}

1- S. Chinenye, A.E. Uloko, A.O. Ogbera, E.N. Ofoegbu, O.A. Fasanmade, A.A. Fasanmade, O.O. Ogbu (2012): Profile of Nigerians with diabetes mellitus - Diabcare Nigeria study group 2008: results of a multicenter study .Ind. J. Endocrinol. Metab., 16 :558-564

2- E.K. Chuhwak, S.D. Pam (2007): Diabetes coexisting with chronic liver disease: clinical features and response to therapy. Niger J. Med., $16: 156-$ 160

3- S. Yim, A. Malhotra, A. Veves (2007): Antioxidants and CVD in diabetes: where do we stand now?. Curr. Diab. Rep., 7: 8-13

4- M. Brownlee (2003): A radical explanation for glucose-induced beta cell dysfunction. J. Clin. Invest., 112: 1788-1790

5- Noboru Toda', Takeshi Imamura, Tomio Okamura (2010): Alteration of nitric oxide-mediated blood flow regulation in diabetes mellitus. Pharmacology \& Therapeutics 127:189-209

6- Melvin R. Hayden , James R. Sowers (2008): Treating hypertension while protecting the vulnerable islet in the cardiometabolic syndrome. Journal of the American Society of Hypertension 2 (4): 239-266.

7- Ceriello A (2006): Controlling oxidative stress as a novel molecular approach to protecting the vascular 
wall in diabetes. Curr Opin Lipidol.; 17(5): 510518.

8- S. Del Guerra, V. D’Aleo, R. Lupi, M. Masini, M. Bugliani U. Boggi, F. Filipponi, P. Marchetti (2009): Effects of exposure of human islet betacells to normal and high glucose levels with or without gliclazide or glibenclamide. Diabetes \& Metabolism 35 (4): 293-298

9- K. Kimoto, K. Suzuki, T. Kizaki, Y. Hitomi, H. Ishida, H. Katsuta et al. (2003): Gliclazide protects pancreatic beta-cells from damage by hydrogen peroxide. Biochem Biophys Res Commun, 303: 112-119

10-Lu-Lu Chen, Fan Yu, Tian-shu Zeng, Tian-shu Zeng, Yun-fei Liao, Yun-fei Liao, Yu-ming Li, Yuming Li, Hong-cheng Ding (2011): Effects of gliclazide on endothelial function in patients with newly diagnosed type 2 diabetes. European Journal of Pharmacology 659 (2-3): 296-301

11-Thomas Münzel, Tommaso Gori Nebivolol (2009): The Somewhat-Different $\beta$-Adrenergic Receptor Blocker. Journal of the American College of Cardiology, 54 (16): 1491-1499.

12-William B White, L. Michael Prisant, Jackson T Wright (2000): Management of patients with hypertension and diabetes mellitus: advances in the evidence for intensive treatment. The American Journal of Medicine, 108(315):238-245

13-Tahara, A.; Matsuyama-Yokono, A.; Nakano, R.; Someya, Y.; Hayakawa, M.; and Shibasaki, M. (2009): Antihyperglycemic effects of ASP8497 in streptozotocin-nicotinamide induced diabetic rats: comparison with other dipeptidyl peptidase-IV inhibitors. Pharmacological reports; 61 (5): 899-908.

14-B.Murali,Dhananjay N.and Ramiesh K.Goyal (2003): Effect of chronic treatment with losartan on streptozotocin-induced renal dysfunction. Molecular and Cellular Biochemistry 249: 85-90.

15-P. Palsamy, S. Sivakumar, S. Subramanian (2010): Resveratrol attenuates hyperglycemia-mediated oxidative stress, proinflammatory cytokines and protects hepatocytes ultrastructure in streptozotocin-nicotinamide-induced experimental diabetic rats.Chemico-Biological Interactions, 186 (2): 200-210.

16-Adriana Georgescu, Doina Popov, Emanuel Dragan, Elena Dragomir, Elisabeta Badila (2007): Protective effects of nebivolol and reversal of endothelial dysfunction in diabetes associated with hypertension. European Journal of Pharmacology 570 (1-3): 149-158.

17-Weitgasser, R.; Davalli, A.M.; and Weir, G.C. (1999): Measurement of glucose concentrations in rats: differences between glucose meter and plasma laboratory results. Diabetologia; 42 (2): 256.

18-Krebs (1950): Physiological salt solutions. Biochem. Bphysiol; Aorta; 4; 249

19-Ghosh, M.N. (1971): Fundamentals of experimental pharmacology. First edition Scientific Book Agency. Calcutta.
20-Furchgott R.F. (1960): Spiral-cut strips of rabbit aorta for in vitro studies of response of arterial smooth muscles. Methode. Med. Res; 8: 177-186.

21-Van Rossum and Van der Brink (1962): Arch pharmacodynamic. 183-200

22-Armitage, P.; and Berry, G. (1994): Statistical methods in medical research, $3^{\text {rd }}$ edition; pp 620. Blackwell Scientific Publications, Oxford. London.

23-Fierabracci, V.; Tata,V.D.; Pocai, A.; Novelli, M.; Barbera, A. and Masiello, M. (2002): Oral tungstate treatment improves only transiently alternation of glucose metabolism in a new rat model of type 2 diabetes.Endocrine;19(2):177-184

24-R.C. O'Brien, M. Luo, N. Balazs, J. Mercuri (2000): In vitro and in vivo antioxidant properties of gliclazide .J. Diabetes Complications, 14: 20

25-P. Pérez-Matute, M.A. Zulet, J.A. Martínez (2009): Reactive species and diabetes: counteracting oxidative stress to improve health Curr. Opin. Pharmacol., 9 : 771-779.

26-JennaLynn Styskal, Holly Van Remmen, Arlan Richardson, Adam B. Salmon (2012): Oxidative stress and diabetes What can we learn about insulin resistance from antioxidant mutant mouse models? Free Radical Biology and Medicine 52(1): 46-58.

27-Selvaraj Sivakumar, Sorimuthu Pillai Subramanian (2009):Pancreatic tissue protective nature of DPinitol studied in streptozotocin-mediated oxidative stress in experimental diabetic rats.European Journal of Pharmacology 622 (1-3): 65-70.

28-Kahkashan Rashid, Joydeep Das, Parames C. Sil (2013): Taurine ameliorate alloxan induced oxidative stress and intrinsic apoptotic pathway in the hepatic tissue of diabetic rats. Food and Chemical Toxicology 51: 317-329.

29-Helen Imrie, Afroze Abbas, Mark Kearney (2010): Insulin resistance, lipotoxicity and endothelial dysfunction. Biochimica et Biophysica Acta (BBA)-Molecular and Cell Biology of Lipids 1801 (3): 320-326.

30-R. Rossi, E. Cioni, A. Nuzzo, G. Origliani, M.G. Modena (2005): Endothelial-dependent vasodilation and incidence of type 2 diabetes in a population of healthy postmenopausal women. Diabetes Care, 28 : 702-707

31-Schernthaner G. (2003): Gliclazide modified release: a critical review of pharmacodynamic, metabolic, and vasoprotective effects. Metabolism 52: 29-34.

32-Ganapathy Saravanan, Ponnusamy Ponmurugan (2012): Ameliorative potential of S-allylcysteine: Effect on lipid profile and changes in tissue fatty acid composition in experimental diabetes. Experimental and Toxicologic Pathology 64 (6): 639-644.

33-Poulter NR (2009): Blood pressure and glucose control in subjects with diabetes: new analyses from Advance. J Hypertens Suppl 27(1): S3-8.

34-Camila Manrique, Guido Lastra, Javad Habibi, Lakshmi Pulakat, Rebecca, Roger Tilmon, William DuranteSchneider, Jenna Rehmer, Melvin R. Hayden, Carlos M. Ferrario, Adam Whaley- 
Connell, James R. Sowers (2011): Nebivolol improves insulin sensitivity in the TGR(Ren2)27 rat. Metabolism 60(12): 1757-1766.

35-Ertuğrul Uzar, Abdullah Acar, Osman Evliyaoğlu, Uğur Fırat, Kağan Kamasak, Cüneyt Göçmez, Harun Alp, Adnan Tüfek, Nebahat Taşdemir, Atilla İlhan (2012): The anti-oxidant and anti-apoptotic effects of nebivolol and zofenopril in a model of cerebral ischemia/reperfusion in rats Progress in Neuro-Psychopharmacology and Biological Psychiatry 36 (1): 22-28.

36-B.K. Cole, S.R. Keller, R. Wu et al. (2010): Valsartan protects pancreatic islets and adipose tissue from the inflammatory and metabolic consequences of a high-fat diet in mice. Hypertension 55: 715-721.

37-X. Zhou, L. Ma, J. Habibi et al. (2010): Nebivolol improves diastolic dysfunction and myocardial remodeling through reductions in oxidative stress in the Zucker obese rat. Hypertension, 55: 880-888.
38-A. Parenti, S. Filippi, S. Amerini, H.J. Granger, A. Fazzini, F. Ledda (2000): Inositol phosphate metabolism and nitric oxide synthase activity in endothelial cells are involved in the vasorelaxant activity of nebivolol J. Pharmacol. Exp. Ther. 292: 698-703.

39-Filomena de Nigris, Francesco Paolo Mancini, Maria Luisa Balestrieri, Russell Byrns, Carmela Fiorito, Sharon Williams-Ignarro, Antonio Palagiano, Ettore Crimi, Louis J. Ignarro, Claudio Napoli (2008): Therapeutic dose of nebivolol, a nitric oxide-releasing $\beta$-blocker, reduces atherosclerosis in cholesterol-fed rabbits. Nitric Oxide 19 (1): 57-63.

40-Rahul Agrawal, Albert Lichtenthal, Carsten Milbredt (2002): Lipid profile of hypertensive patients with hyperlipidemia and coronary artery disease after treatment with nebivolol: a betablocker with enhanced nitric oxide release.Journal of the American College of Cardiology, 39: 210A. 